Check for updates

Cite this: RSC Adv., 2019, 9, 27692

\title{
Sustainable and efficient sugar production from wheat straw by pretreatment with biogas digestate
}

\author{
Forough Momayez, ${ }^{\text {ac }}$ Keikhosro Karimi (D) ab and Ilona Sárvári Horváth (DD *c
}

The use of liquid fraction of biogas digestate (LFBD) instead of fresh water (hydrothermal) for the pretreatment of wheat straw was evaluated to improve the yield of released sugars during the following hydrolysis step. The pretreatments were conducted at temperatures of 130,160 , and $190{ }^{\circ} \mathrm{C}$ for 30 and $60 \mathrm{~min}$. In most of the cases, pretreatment using LFBD led to higher glucose yields and higher total sugars concentrations, compared to those obtained after applying hydrothermal pretreatments. The increase of temperature resulted in an increase in sugars during the enzymatic hydrolysis. The highest yields of glucose (about 59\%) were observed after treatments at $190{ }^{\circ} \mathrm{C}$ for $60 \mathrm{~min}$, independently of which type of pretreatment was applied and at $190^{\circ} \mathrm{C}$ for 30 min using LFBD. Treatment, with LFBD at $190{ }^{\circ} \mathrm{C}$ and for $60 \mathrm{~min}$, resulted in glucose and xylose concentrations of $7.36 \mathrm{~g} \mathrm{~L}^{-1}$ and $2.41 \mathrm{~g} \mathrm{~L}^{-1}$, respectively, after the subsequent hydrolysis for $48 \mathrm{~h}$. However, the FTIR analysis indicated that the crystallinity index remained rather constant after treatment. Both FTIR and compositional analysis showed that the removal of hemicelluloses was the main effect of the pretreatment.

Received 10th July 2019

Accepted 28th August 2019

DOI: $10.1039 / c 9 r a 05285 b$

rsc.li/rsc-advances sugars via hydrolysis of straw and then converting them into chemicals and biofuels is of economic interest. However, the recalcitrant structure of lignocellulosic biomass limits the degradation of polysaccharides into monomeric sugars. To increase the digestibility of this biomass, the disruption of its complex lignocellulosic network is needed before hydrolysis. Consequently, the application of some kind of pretreatment is a necessary step aiming to break down the structural barriers and enhance the sugar yield in subsequent processes. ${ }^{\mathbf{1 0 - 1 4}}$ Considerable efforts have been made in this field, including development and investigations of various chemical, physical, and biological pretreatment technologies. ${ }^{15-18}$ However, each pretreatment method has its own advantages and disadvantages. Liquid hot water (LHW) pretreatment is one of the most desired pretreatment strategies because of its low cost in comparison with other technologies, i.e., lime, diluted acid, or ammonia fiber explosion pretreatments. Furthermore, as no chemical is added in this process, handling of the downstream residue is also easier. ${ }^{19}$ LHW pretreatment has the potential of removing hemicellulose from biomass structure, while minimizing the hydrolysis of cellulose and the sugar degradation. It has been reported that $80 \%$ of hemicellulose was removed after LHW pretreatment of sugarcane bagasse ${ }^{20,21}$ and corn fiber. ${ }^{22}$ Utilization of acids, bases, and other chemicals such as ionic liquids in lignocellulosic feedstock pretreatment was also employed to improve process effectiveness. ${ }^{23-25}$ Beside solubilization of hemicellulose, using these chemicals can remove lignin and reduce lignin-cellulose-xylan interactions, leading to higher cellulose digestibility. ${ }^{26-28}$ Despite increasing sugar yield in subsequent hydrolysis processes, adding chemicals for the pretreatment are connected to some drawbacks including increasing costs,
aDepartment of Chemical Engineering, Isfahan University of Technology, Isfahan
84156-83111, Iran
${ }^{b}$ Industrial Biotechnology Group, Research Institute for Biotechnology and
Bioengineering, Isfahan University of Technology, Isfahan 84156-83111, Iran
${ }^{c}$ Swedish Centre for Resource Recovery, University of Borås, 50190 Borås, Sweden.
E-mail: ilona.horvath@hb.se; Tel: +46334354684 
equipment corrosion, high energy consumption, $\mathrm{pH}$ neutralization requirement, and formation of inhibitory by-products. ${ }^{1,29,30}$ Therefore, using a waste stream, that consists of effective elements, such as acids and bases, instead for the pretreatment would be more beneficial.

In the biogas process, the digestate is separated into liquid and solid fractions. The solid part can be used for animal feeding or for farmland fertilizer, nevertheless managing the liquid part can be a serious problem. ${ }^{31,32}$ This liquid fraction is not rich enough in nutrients to be used as fertilizer, while its nitrogen content is high enough to cause nitrogen pollution. Hence, releasing this liquid fraction to the nature with no further processing would lead to environmental problems. Diluting with water to decrease the concentration of hazardous or toxic compounds is a traditional way, however this method would increase the volume of wastewater produced. ${ }^{33-35}$ On the other hand, utilizing this liquid waste stream for suitable pretreatment can be beneficial. The presence of volatile fatty acids, phosphorus, nitrogen, calcium, potassium and sulfur in this waste liquid can increase the efficiency of the pretreatment. ${ }^{36,37}$

In this study, wheat straw, a renewable low-cost lignocellulosic material, was utilized to produce fermentable sugars. LHW pretreatment at different temperatures and times was performed on straw and the results were compared to those obtained by using the liquid fraction of biogas digestate (LFBD) for the pretreatment at same process conditions. The digestibility of untreated and pretreated wheat straw was evaluated via enzymatic hydrolysis. Furthermore, compositional as well as structural changes caused by the pretreatment were also studied using Fourier transform infrared (FTIR) spectroscopy and scanning electron microscopy (SEM).

\section{Materials and methods}

\subsection{Raw materials}

The wheat straw used in this study was obtained from a local farm in Shahreza, Isfahan, Iran. The collected straw was milled and then meshed to achieve a particle size between 0.1 and $0.8 \mathrm{~mm}$ before pretreatment. The sieved straw was stored at room temperature for further use. The digestate residue was taken from a $3000 \mathrm{~m}^{3}$ large scale anaerobic digester treating the organic fraction of municipal solid waste (Borås Energi och Miljö $\mathrm{AB}$, Borås, Sweden). The digestate contained $4900 \mathrm{mg}$ $\mathrm{kg}^{-1}$ nitrogen, $3600 \mathrm{mg} \mathrm{kg}{ }^{-1}$ ammonium, $0.35 \mathrm{~kg}$ per ton phosphorus, $1.1 \mathrm{~kg}$ per ton potassium, $0.83 \mathrm{~kg}$ per ton calcium, and $0.28 \mathrm{~kg}$ per ton sulfur (Robert Kjellstrand, 2017-09-14, personal communication). The concentrations of acids in the digestate were $0.454 \mathrm{~g} \mathrm{~L}^{-1}$ acetic acid, and $0.051 \mathrm{~g} \mathrm{~L}^{-1}$ propionic acid. This residue was first centrifuged for $10 \mathrm{~min}$ at $4500 \mathrm{rpm}$ and then the supernatant, as the liquid fraction of biogas digestate (LFBD), was used for the pretreatment.

\subsection{Pretreatment of wheat straw}

The pretreatments were conducted in $150 \mathrm{~mL}$ tubular stainless steel reactors, tolerating high temperature and pressure. An amount of $6.5 \mathrm{~g}$ of dried wheat straw was well mixed with a sufficient amount of water or LFBD to obtain a solid-to-liquid ratio of $1: 15$. The reactors were then closed tightly and put in the oil bath with desired temperatures of 130,160 or $190{ }^{\circ} \mathrm{C}$ used for the treatments and the treatment time was 30 or $60 \mathrm{~min}$. At the end of the time period applied, the reactors were immediately immersed in cooling water to reduce the pressure and temperature. The pretreated wheat straw was then separated from the pretreatment liquor by filtration and manual squeezing. The solid residue was dried at room temperature to a constant weight. The dried solid residue was weighted and the solid recovery at different pretreatment conditions was calculated. The pretreated wheat straw samples were then maintained in plastic bags in the cold room $\left(4^{\circ} \mathrm{C}\right)$ until further investigations.

\subsection{Enzymatic hydrolysis}

The enzymatic hydrolysis was conducted in $118 \mathrm{~mL}$ glass bottles using $50 \mathrm{mM}$ sodium acetate buffer at $\mathrm{pH}$ 4.8. The bottle containing $0.25 \mathrm{~g}$ of treated or untreated straw was autoclaved at $121{ }^{\circ} \mathrm{C}$ for $20 \mathrm{~min}$ to avoid any contamination. The samples were then cooled to room temperature. Then $10 \mathrm{~mL}$ of buffer was added to achieve a substrate concentration of $25 \mathrm{~g} \mathrm{~L}^{-1}$ and each sample was then well mixed. The cellulase enzyme, Cellic CTec2, was provided by Novozyme, Denmark and used for the enzymatic hydrolysis process. The enzyme load was 20 FPU per $g$ substrate. The enzymatic hydrolysis was performed in a shaker at $50{ }^{\circ} \mathrm{C}$, and $120 \mathrm{rpm}$ for $48 \mathrm{~h}$. To determine the amount of released sugars, liquid samples were taken after 24 and $48 \mathrm{~h}$ of hydrolysis time. The concentration of glucose and xylose was then determined by high performance liquid chromatography (HPLC, Waters 2695, Waters Corporation, Milford, USA). A hydrogen ion-based ion-exchange column (Aminex HPX-87H, Bio-Rad, USA) at $60{ }^{\circ} \mathrm{C}$ together with a Micro-Guard cation-H guard column (Bio-Rad, USA) was used for the measurements. The eluent was $\mathrm{H}_{2} \mathrm{SO}_{4}$ with concentration of $5 \mathrm{mM}$ and at a flow rate of $0.6 \mathrm{~mL} \mathrm{~min}^{-1}$.

\subsection{Analytical methods}

Total solids (TS) of the treated and untreated samples were measured by keeping the samples in an oven at $105{ }^{\circ} \mathrm{C}$ until constant weight, and then the dried samples was further heated in a furnace at $575{ }^{\circ} \mathrm{C}$, to determine the volatile solids (VS) content, as it is described in details by Sluiter et $a l .{ }^{38}$ The activity of cellulase enzyme was determined to $90 \mathrm{FPU} \mathrm{mL}^{-1}$ following the standard method recommended by Adney and Baker. ${ }^{39}$

The composition of the straw samples was determined according to the method published by the National Renewable Energy Laboratory (NREL, USA), ${ }^{40}$ and the main steps are summarized as follows: $0.3 \mathrm{~g}$ of samples were treated with $3 \mathrm{~mL}$ $\mathrm{H}_{2} \mathrm{SO}_{4}(72 \% \mathrm{w} / \mathrm{w})$ for $1 \mathrm{~h}$ at $30{ }^{\circ} \mathrm{C}$. The mixture was then diluted with $84 \mathrm{~mL}$ deionized water to $4 \% \mathrm{H}_{2} \mathrm{SO}_{4}(\mathrm{w} / \mathrm{w})$ and then autoclaved for $1 \mathrm{~h}$ at $121{ }^{\circ} \mathrm{C}$. After filtration, the liquid fraction was analyzed by high-performance liquid chromatography (HPLC, Waters 2695, Waters Corporation, Milford, USA) to determine the concentration of monomeric sugars. The HPLC was equipped with an Aminex HPX-87P column (Bio-Rad, USA) and RI detector (Jasco International Co., Tokyo, Japan). The column 
Table 1 Total solid, volatile solid, and solid recovery of untreated and pretreated wheat straw at different conditions

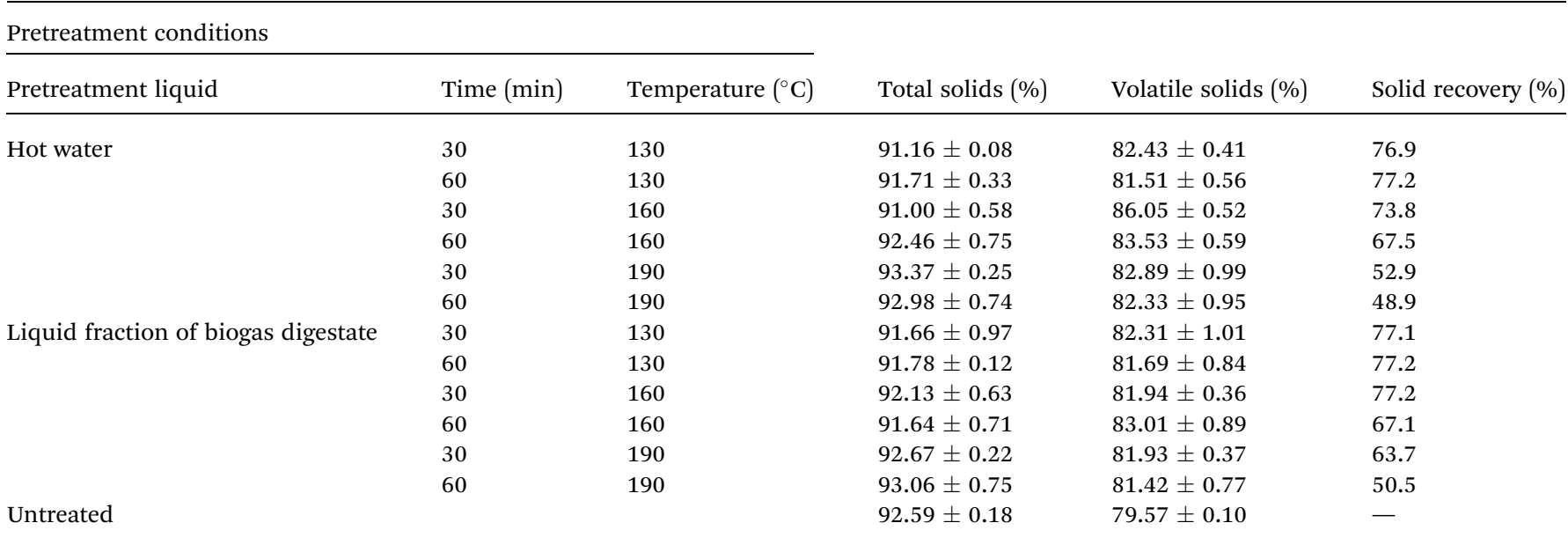

temperature was $85{ }^{\circ} \mathrm{C}$ and deionized water with flow rate of 0.6 $\mathrm{mL} \min ^{-1}$ was applied as mobile phase. The acid soluble lignin (ASL) was determined by measuring the absorbance of the liquid at $240 \mathrm{~nm}$. The solid fraction was dried at $105{ }^{\circ} \mathrm{C}$ overnight in an oven and then placed in the furnace at $575{ }^{\circ} \mathrm{C}$ until constant weight. The weight of the ash was measured and used to calculate the content of acid insoluble lignin (AIL).

To investigate the effect of pretreatment on chemical structure and crystallinity of wheat straw, FTIR spectroscopy was used. The spectrometer (Bruker Tensor 27 FT-IR, USA) was equipped with an universal ATR (attenuated total reflectance) accessory and deuterated triglycine sulfate (DTGS) detector. Initially, the samples were well mixed with $\mathrm{KBr}$ at a weight ratio of $1: 100$ and then pressed into discs. The spectra were recorded from 600 to $4000 \mathrm{~cm}^{-1}$, with an average of 60 scans and $4 \mathrm{~cm}^{-1}$ resolution.

Scanning electron microscopy (SEM) images of treated and untreated wheat straw samples were obtained to study the effect of pretreatment on surface morphology. All samples were freeze-dried for $24 \mathrm{~h}$ and then coated with gold (Emitech Sputter Coater SC7640,
Quorum Technologies, UK). Images at magnifications of 250, 500, and 700 were taken by SEM (Zeiss, Germany) at $13 \mathrm{kV}$.

\subsection{Statistical analysis}

Statistical validation of achieved results was performed by Analysis of variance (ANOVA) test. SAS software and NewmanKeuls or Student-Newman-Keuls (SNK) method with 95\% confidence were used for comparing and estimating the significant difference between the means.

\section{Results and discussion}

\subsection{Chemical composition of wheat straw before and after pretreatment}

Total solids (TS), volatile solids (VS) for untreated and pretreated wheat straw and the solid recovery at different treatment conditions were measured and are reported in Table 1. No serious changes were detected in the TS and VS contents of the samples after pretreatment, however the solid recovery has decreased by increasing pretreatment temperature.

Table 2 Compositional analysis of untreated and pretreated wheat straw (All data are calculated based on the oven dried weight of the samples.)

Pretreatment conditions

\begin{tabular}{|c|c|c|c|c|c|c|c|}
\hline Pretreatment medium & Time (min) & Temperature $\left({ }^{\circ} \mathrm{C}\right)$ & Glucan (\%) & Xylan (\%) & Arabinan (\%) & AIL (\%) & ASL (\%) \\
\hline \multirow[t]{5}{*}{ Hot water } & 30 & 130 & $34.24 \pm 0.81$ & $19.74 \pm 0.56$ & $2.23 \pm 0.31$ & $15.81 \pm 0.20$ & $3.79 \pm 0.32$ \\
\hline & 60 & 130 & $35.46 \pm 0.68$ & $18.34 \pm 0.07$ & $1.84 \pm 0.12$ & $16.25 \pm 0.36$ & $3.47 \pm 0.16$ \\
\hline & 60 & 160 & $37.46 \pm 0.06$ & $18.47 \pm 0.30$ & $1.05 \pm 0.00$ & $17.74 \pm 0.41$ & $3.24 \pm 0.06$ \\
\hline & 30 & 190 & $48.40 \pm 0.21$ & $9.39 \pm 0.04$ & $0.00 \pm 0.00$ & $19.85 \pm 0.87$ & $3.05 \pm 0.76$ \\
\hline & 60 & 190 & $48.80 \pm 0.58$ & $2.53 \pm 0.19$ & $0.00 \pm 0.00$ & $23.09 \pm 0.25$ & $3.71 \pm 0.00$ \\
\hline & 30 & 160 & $35.11 \pm 0.34$ & $19.20 \pm 0.23$ & $2.06 \pm 0.02$ & $16.59 \pm 0.56$ & $3.71 \pm 0.00$ \\
\hline & 60 & 160 & $37.94 \pm 0.36$ & $19.30 \pm 0.46$ & $1.88 \pm 0.10$ & $16.11 \pm 0.10$ & $3.35 \pm 0.02$ \\
\hline & 30 & 190 & $40.73 \pm 0.21$ & $15.26 \pm 0.17$ & $0.00 \pm 0.00$ & $16.96 \pm 0.48$ & $3.79 \pm 0.01$ \\
\hline & 60 & 190 & $45.32 \pm 1.00$ & $11.34 \pm 0.25$ & $0.00 \pm 0.00$ & $17.28 \pm 0.13$ & $3.66 \pm 0.01$ \\
\hline Untreated & & & $30.38 \pm 0.40$ & $16.97 \pm 0.00$ & $1.92 \pm 0.04$ & $14.44 \pm 0.92$ & $4.45 \pm 0.05$ \\
\hline
\end{tabular}




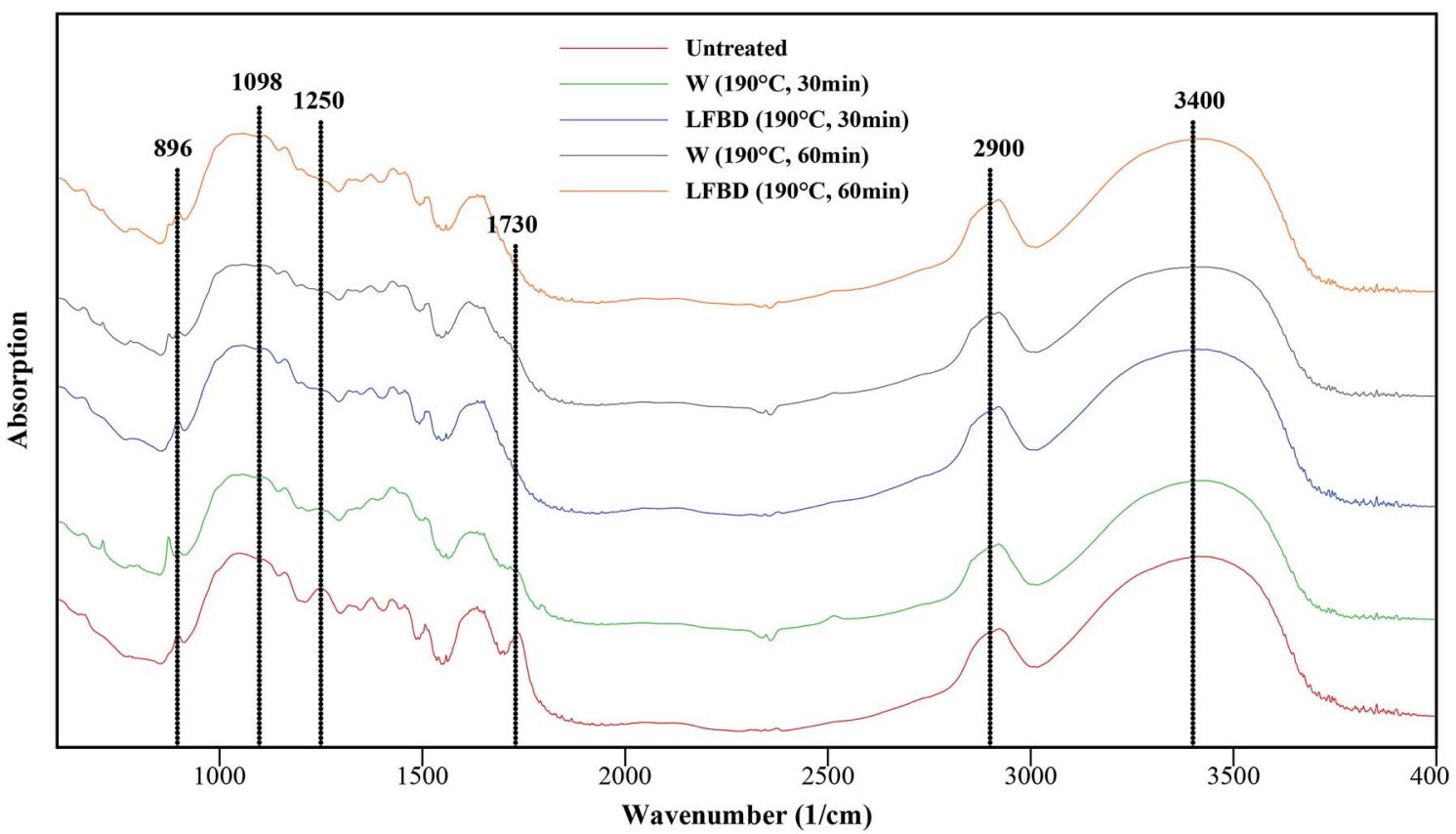

Fig. 1 FTIR spectra of untreated vs. pretreated samples at $190^{\circ} \mathrm{C}(\mathrm{W}=$ hot water; LFBD $=$ liquid fraction of biogas digestate).

Consequently, more solid was released during pretreatment at more severe conditions as it was expected. The minimum solid recovery was around $50 \%$ for straw treated at $190{ }^{\circ} \mathrm{C}$ for $60 \mathrm{~min}$ both with LFBD and with hot water (Table 1).

The compositions of original and treated wheat straw are presented in Table 2. As in other lignocellulosic materials, the carbohydrate fraction is the main constituent, with $30.4 \%$ glucan and $17 \%$ xylan, for dried untreated wheat straw. This high content of carbohydrates makes this biomass an attractive feedstock for biofuel production utilizing the sugars. After treatment at 130 and $160{ }^{\circ} \mathrm{C}$ for 30 and $60 \mathrm{~min}$ there was only a slight increase in the glucan content, however, when treating at more severe conditions, i.e., at $190{ }^{\circ} \mathrm{C}$ a larger increment in the glucan content was observed compared to that in the untreated straw. The highest glucan content, of $48.8 \%$, was achieved for straw treated with hot water at $190{ }^{\circ} \mathrm{C}$ for $60 \mathrm{~min}$ (Table 2). This is the result of the destruction and solubilization of hemicelluloses at these conditions. In line with these findings, the xylan content of straw treated at $190{ }^{\circ} \mathrm{C}$ for $60 \mathrm{~min}$ with hot water or with LFBD decreased to 2.53 or to $11.34 \%$, respectively. Furthermore, a complete omission of the arabinan fraction was achieved after treatment at these conditions (Table 2).

The acid insoluble lignin (AIL) and the acid soluble lignin (ASL) content accounted for $14.4 \%$ and $4.5 \%$, respectively, in the dried untreated straw. According to the results obtained, delignification of straw did not occur during the pretreatments with hot water or LFBD under the investigated conditions. In conclusion, treatments with hot water or LFBD had similar effects regarding compositional changes in the wheat straw (Table 2). Both liquids caused partial removal of hemicelluloses resulting in an increment in the glucan content. The amounts of xylan decreased more due to the treatment with hot water compared to that with LFBD regarding treatments at same conditions (Table 2).

Previously, Petersen et $a l .{ }^{41}$ reported that at least $90 \%$ of the lignin content is recovered in the solid residue after hydrothermal treatment under all of the conditions $\left(185-205^{\circ} \mathrm{C}\right.$ and 6-12 min) investigated. Furthermore, they indicated that the hemicellulose recovery in the solid fraction had decreased by increasing the severity factor, i.e. $\log R_{0}=t \times \exp \left(\frac{T-100}{14.75}\right)$, where $R_{0}=$ severity factor, $t=$ time ( $\left.\mathrm{min}\right), T=$ temperature $\left({ }^{\circ} \mathrm{C}\right)$. Perez et al. $^{42}$ also showed that only $6 \%$ of the xylan present in the raw wheat straw remains in its solid structure after hot water pretreatment at $200{ }^{\circ} \mathrm{C}$ for $40 \mathrm{~min}$. They concluded that an increase in the treatment temperature and time will lead to a higher degree of hemicellulose solubilization. These results are similar to those reported in the literature regarding similar treatment procedures for other kinds of lignocellulosic feedstocks as well. ${ }^{43-46}$

\subsection{FTIR and SEM analyses}

Fig. 1 and Table 3 present the results of FTIR analyses for some treated samples compared to those for untreated wheat straw; the wavelength attributed to different functional groups and their appearance in the lignocellulosic structure can also be found in the table. The peak at $1510 \mathrm{~cm}^{-1}$ represents the aromatic ring stretch vibration in lignin, which was applied as an internal reference band for normalizing to compare the spectra quantitatively. ${ }^{47}$ The peak around $3400 \mathrm{~cm}^{-1}$ is attributed to the $\mathrm{OH}$ stretching, and a reduction in this peak intensity after the treatments indicates a disruption of hydrogen bonds in cellulose. ${ }^{48}$ The peak at $2900 \mathrm{~cm}^{-1}$ is indicative for $\mathrm{C}-\mathrm{H}$ stretching, which was reduced after hot water pretreatment, 


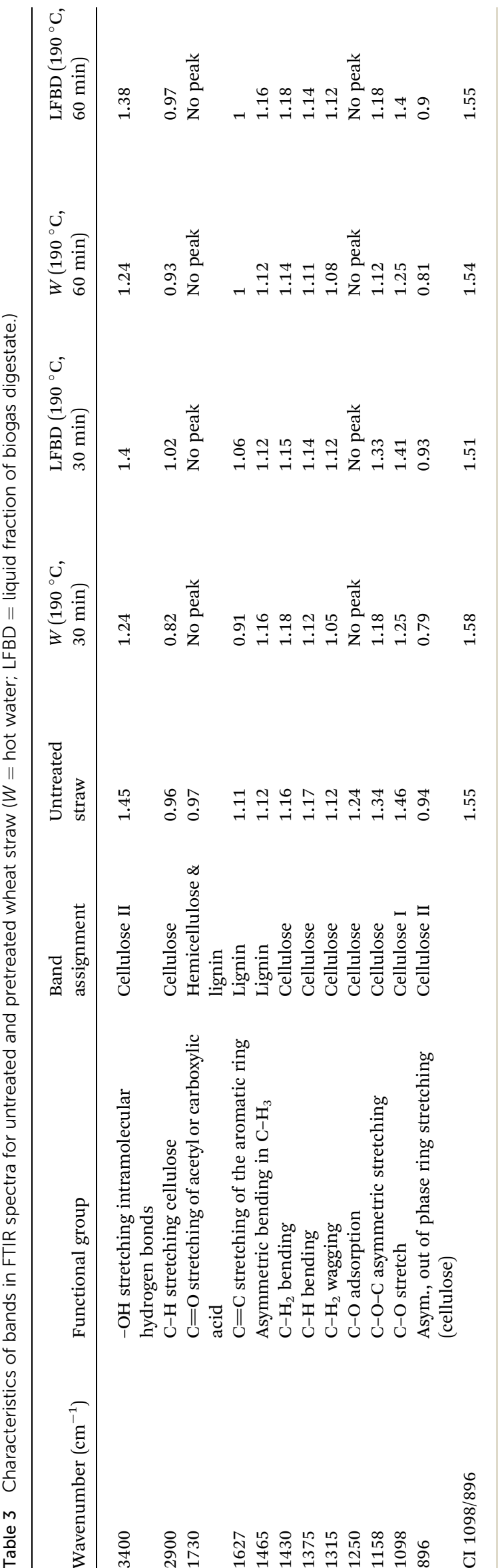

demonstrating a rupture of the methyl and methylene parts of cellulose. ${ }^{49-51}$ For all treated samples, the peak intensity at $1730 \mathrm{~cm}^{-1}$ had a notable reduction. This band position is assigned to the uronic ester and hemicellulose acetyl groups or ester linkage of carboxylic group of the $p$-coumaric and ferulic acids of lignin/hemicelluloses. ${ }^{52}$ In line with the results of the compositional analyses (Table 2), the pretreatment with hot water and LFBD caused the destruction/solubilization of hemicelluloses. The removal of hemicelluloses causes considerable changes in the structure of lignocellulosic materials, leading to easier accessibility for enzymes and microorganisms to the cellulose..$^{48}$ The adsorption peak of the band at $1250 \mathrm{~cm}^{-1}$ was detectable in raw wheat straw, representing the acetyl groups in the structure. However, this band could not be found for the pretreated samples due to the hemicellulose removal as discussed above. ${ }^{49}$

Furthermore, another important result of the pretreatment that can occur is the change in the ratio between crystalline and amorphous cellulose presented in the biomass structure. The absorbance band at $1098 \mathrm{~cm}^{-1}$ is assigned to cellulose I, or high crystalline cellulose, which is a highly resistant structure to hydrolysis, whereas the absorbance band at $896 \mathrm{~cm}^{-1}$ denotes cellulose II, or amorphous cellulose, with greater ability to be hydrolyzed. Hence, the crystallinity index was defined as the absorbance ratio of $A_{1098} / A_{896}{ }^{49,53}$ which is shown for each of the samples treated at $190{ }^{\circ} \mathrm{C}$ in Table 3. However, no notable changes occurred in the crystallinity index after treatments at these conditions. Though the peak intensity referred to cellulose I has decreased after the pretreatment, but as a consequence of the treatment the peak for cellulose II has also declined and the crystallinity index remained constant. In another study, it was also found that hydrothermal pretreatment of wheat straw had no significant effect on the crystallinity of the samples. ${ }^{54}$

To investigate changes in the microscopic structure of straw after pretreatment SEM images were captured and these are shown in Fig. 2. The presence of organized and crystalline cellulose fibers is one of the most important obstacles regarding the digestibility of lignocellulosic materials. This organized structure can be seen for untreated straw $(1(\mathrm{a}-\mathrm{c}))$ and also for treated straw at low temperatures (2 and $3(\mathrm{a}-\mathrm{c}))$ on the SEM images presented in Fig. 2. By increasing the severity of the pretreatment conditions ( 4 and $5(\mathrm{a}-\mathrm{c})$ ), a significant morphological modification can be observed. Packed structure of straw was converted to a more porous structure, which is expected to be more accessible for the enzymes during the following degradation process. These observations were previously reported in the literature and also supported with further analyses. ${ }^{55}$

\subsection{Enzymatic hydrolysis}

The performance of the enzymatic hydrolysis was followed up by measuring the concentrations of glucose and xylose released from the samples due to the enzymatic treatment. Fig. 3 shows the amount of released sugars obtained after 24 and $48 \mathrm{~h}$ of hydrolysis times for untreated compared to those for treated 

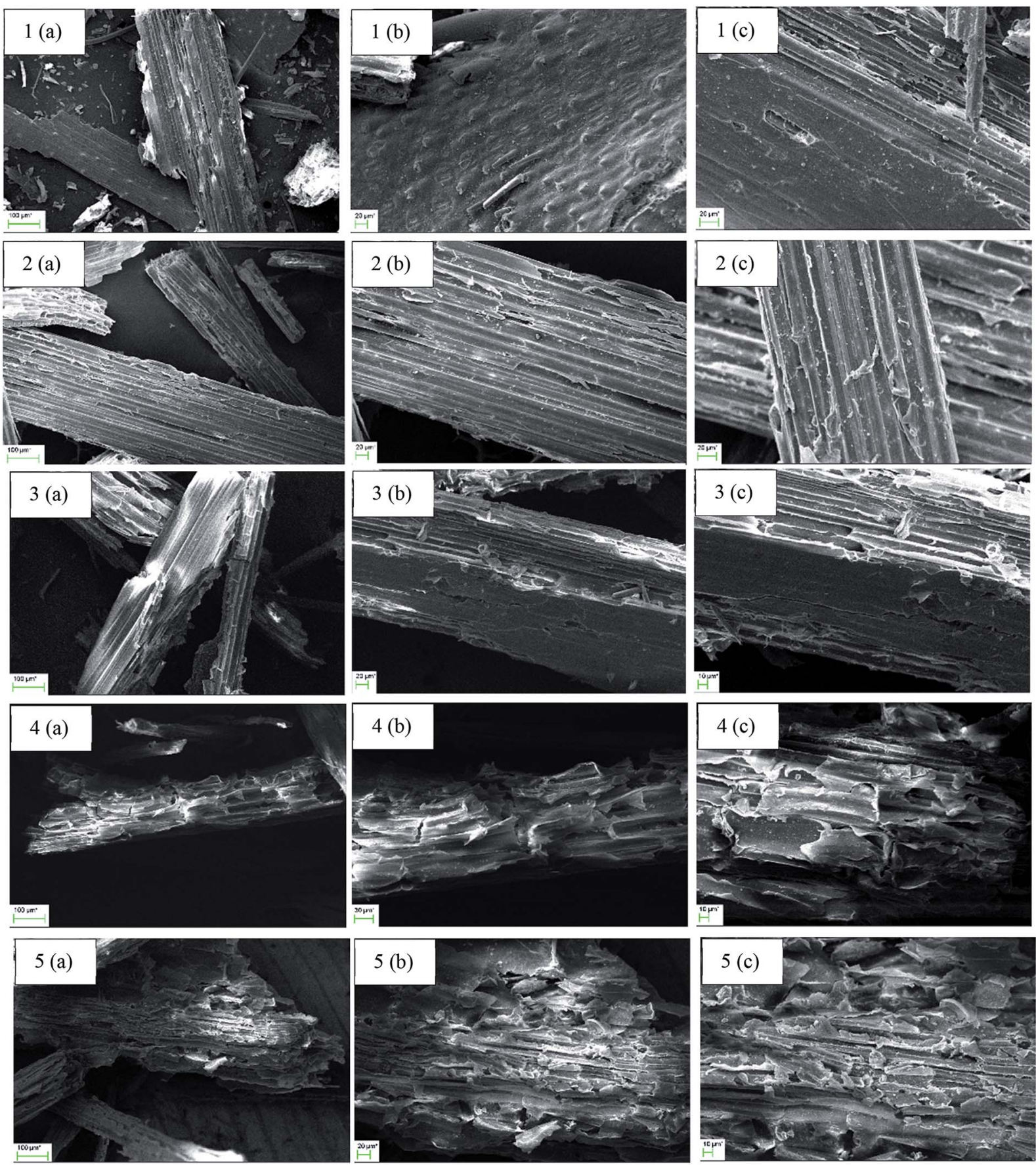

Fig. 2 SEM images of untreated (1) and four pretreated samples of wheat straw treated at the following conditions: hot water $(\mathrm{W})$ at $130{ }^{\circ} \mathrm{C}$ for $60 \mathrm{~min}$ (2); liquid fraction of biogas digestate (LFBD) at $130{ }^{\circ} \mathrm{C}$ for $60 \mathrm{~min}$ (3); $\mathrm{W}$ at $190{ }^{\circ} \mathrm{C}$ for $60 \mathrm{~min}(4)$; LFBD at $190^{\circ} \mathrm{C}$ for $60 \mathrm{~min}(5)$. The images representing magnifications of 250 (a), 500 (b), and 750 (c).

samples. It was found that the digestibility of straw could significantly be increased after pretreatments at high temperature with either hot water or with LFBD. The possible reason behind this improvement might be the removal of hemicelluloses (Table 2) together with changes observed in the cellulose structure (Fig. 1 and 2). The highest glucose release of $8.0 \mathrm{~g} \mathrm{~L}^{-1}$, was obtained from the sample treated with hot water at $190{ }^{\circ} \mathrm{C}$ for $60 \mathrm{~min}$ (Fig. 3). According to the compositional analysis, this sample also showed the highest xylose removal after pretreatment (Table 2). During the enzymatic hydrolysis of straw treated with LFBD at the same conditions almost as high amount of glucose, i.e. $7.4 \mathrm{~g} \mathrm{~L}^{-1}$, was released, indicating the suitability of this waste liquid fraction to be used for the pretreatment. Moreover, when straw was treated with LFBD at severe conditions, a higher xylose concentration was obtained after the hydrolysis compared to that when the straw was 


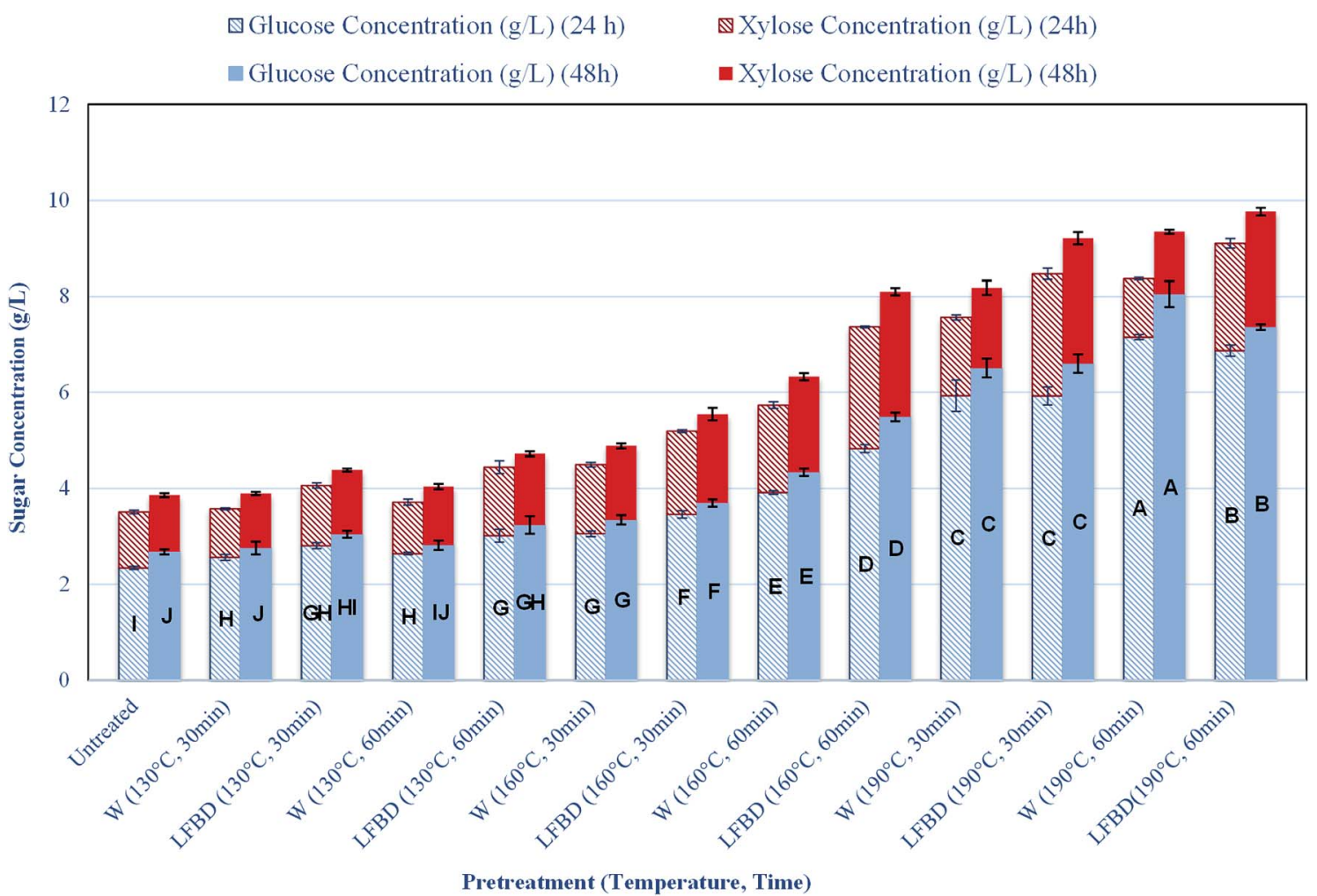

Fig. 3 Enzymatic digestibility of untreated and pretreated wheat straw ( $W=$ hot water; LFBD = liquid fraction of biogas digestate). The columns are representing the total amount of released sugars, showing the sum of glucose (blue) and xylose (red). The reported data are the mean of the results obtained from three repeated tests performed at same conditions. There are no significant differences at a 5\% probability level $(P<0.05)$ among the means marked with the same letter.

treated with hot water at same conditions. The highest xylose concentration of $2.6 \mathrm{~g} \mathrm{~L}^{-1}$ was achieved after $48 \mathrm{~h}$ enzymatic hydrolysis of wheat straw samples pre-treated with LFBD at $190{ }^{\circ} \mathrm{C}$ for $30 \mathrm{~min}$ and at $160^{\circ} \mathrm{C}$ for $60 \mathrm{~min}$. Furthermore, these results also show, that there were no inhibitory compounds presented affecting the enzyme activity in this waste liquid, since high concentrations of sugars were liberated during the hydrolysis. In comparison, only 2.68 and $1.18 \mathrm{~g} \mathrm{~L}^{-1}$, glucose and xylose, respectively was released from untreated wheat straw after $48 \mathrm{~h}$ enzymatic digestion. Moreover, solid residues pretreated at low temperature gave similar amount of glucose concentrations during the hydrolysis as untreated wheat straw (Fig. 3).

Table 4 Glucose yield during enzymatic hydrolysis of untreated and pretreated wheat straw obtained after 24 and $48 \mathrm{~h}$ of hydrolysis time (The reported data correspond to the mean of results obtained from three repeated tests performed at same conditions. There are no significant differences at a $5 \%$ probability level $(P<0.05)$ among the data belonging to a group marked with the same letter.)

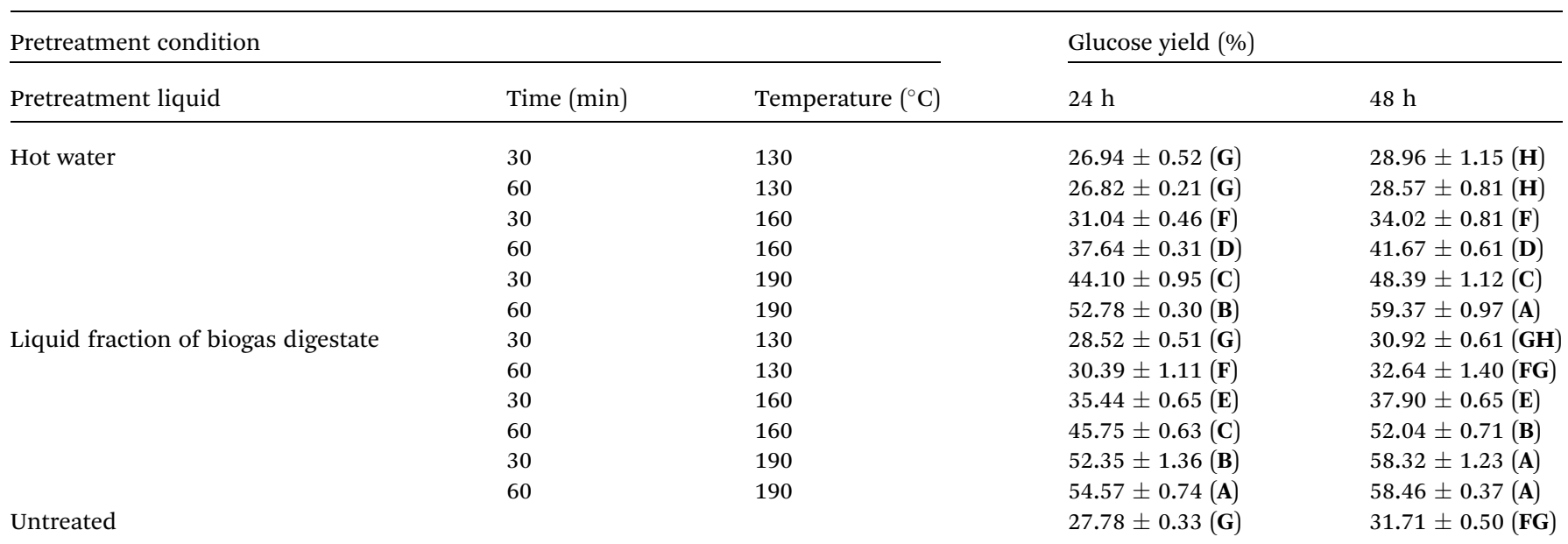




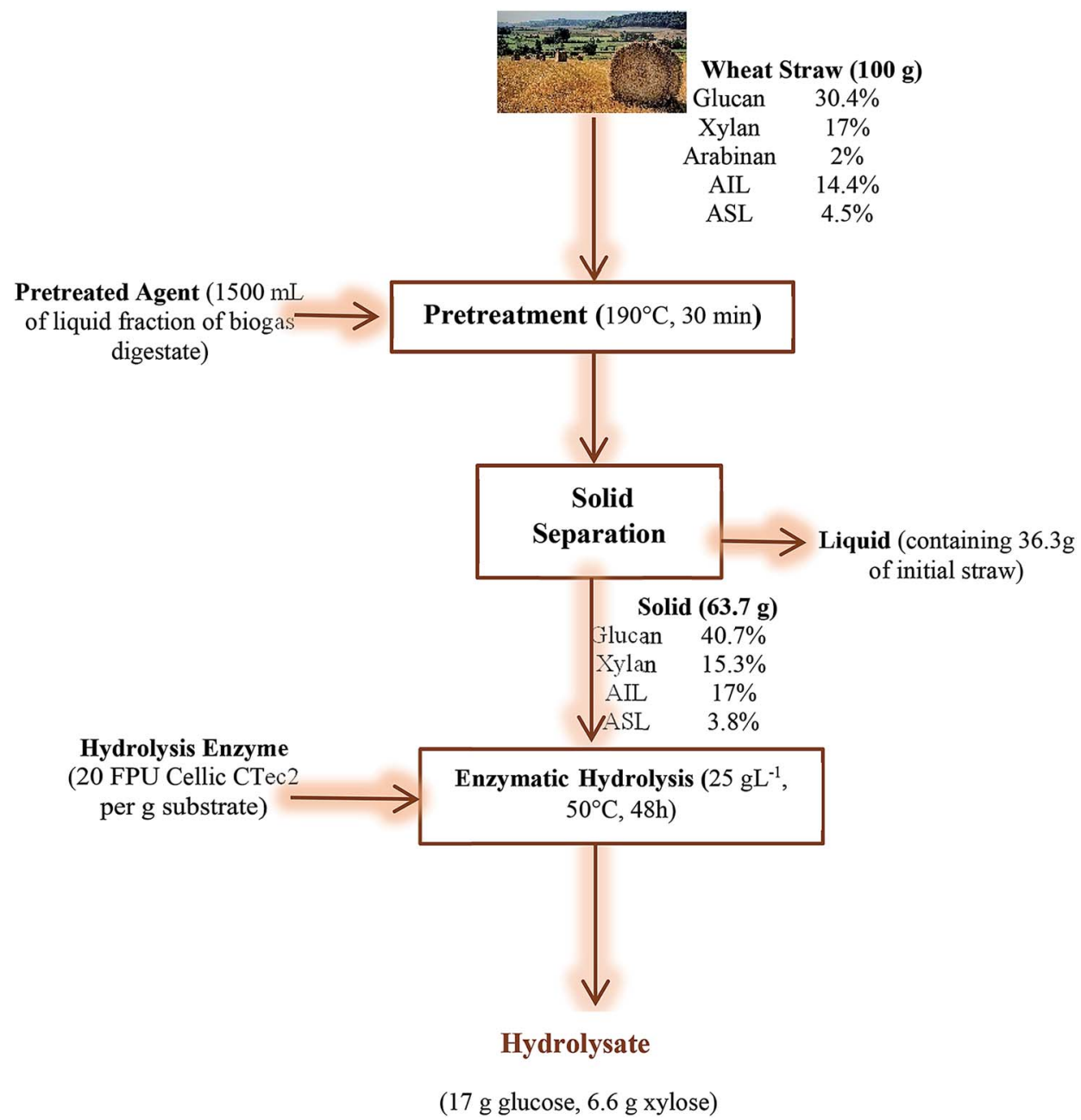

Fig. 4 Overall mass balance over the process steps of wheat straw pretreated with liquid fraction of biogas digestate (LFBD) at $190{ }^{\circ} \mathrm{C}$ with for 30 min followed by enzymatic hydrolysis.

The glucose yield for treated and untreated samples was calculated according to eqn $(1)^{56}$ and is reported in Table 4.

$$
\begin{aligned}
& \text { Enzymatic hydrolysis yield }(\%)= \\
& \frac{\text { produced glucose }\left(\mathrm{g} \mathrm{L}^{-1}\right)}{\text { substrate concentration }\left(\mathrm{g} \mathrm{L}^{-1}\right) \times F \times 1.11} \times 100
\end{aligned}
$$

where $F$ is the glucan fraction in the substrate and the constant 1.11 stands for hydrolysis of glucan to glucose. The highest yields were around $59 \%$, and these were obtained after treatments at $190{ }^{\circ} \mathrm{C}$ and for $60 \mathrm{~min}$, independently if the treatment was carried out with hot water or with LFBD. Moreover, similar yield of glucose could be reached even when the treatment with LFBD was held for only $30 \mathrm{~min}$, while the yield after treatment with hot water at similar conditions was significantly, i.e. about $10 \%$, lower (Table 4). In summary, except for the most severe pretreatment conditions $\left(190{ }^{\circ} \mathrm{C}\right.$ and $\left.60 \mathrm{~min}\right)$, the glucose yield was higher for the samples treated with LFBD compared to those treated with hot water at the same conditions. The presence of effective elements such as nitrogen, ammonium, phosphorus, and acids may be the main reason for the better performance of LFBD. Although each element concentration is low, the effect of all elements together might be considerable. ${ }^{57}$

Although the glucose yield was increased considerably after treatment at severe conditions, the solid recoveries are low at these conditions. Therefore, the actual sugar yields achieved per gram of straw entering the pretreatment process are lower than those reported in Table 4. However, according to the compositional analysis (Table 2), the main target component of the straw for the hydrolysis, i.e., the content of glucose, was increased after the treatment, indicating that the components dissolved due to the pretreatment step are mostly the useless parts. Consequently, by the elimination of these useless components through the pretreatment, the reactor volume can be decreased and also the amount of enzymes required for the hydrolysis will be reduced. ${ }^{58}$

These results are comparable with those reported from previous investigations. The glucose yield after enzymatic hydrolysis of wheat straw treated with ionic liquid, 1-ethyl-3methyl imidazolium diethyl, at $130{ }^{\circ} \mathrm{C}$ for 30 min was $54.8 \% .{ }^{59}$ In another work, the effect of dilute acid pretreatment 
for wheat straw was investigated. Pretreatment with $0.75(\mathrm{v} / \mathrm{v})$ $\mathrm{H}_{2} \mathrm{SO}_{4}$ at $121{ }^{\circ} \mathrm{C}$ for $1 \mathrm{~h}$, resulted in a yield of $74 \%$ regarding the total sugars content. ${ }^{4}$ In another study, the effects of alkaline wet oxidation on wheat straw was investigated using conditions of 10 bar of oxygen pressure at different temperatures and pretreatment times. The highest sugar yield was $85 \%$, obtained from the straw treated at $170{ }^{\circ} \mathrm{C}$ for $10 \mathrm{~min} .^{60}$

\subsection{Overall mass balance}

An overall mass balance throughout the process steps of the treatment of wheat straw using LFBD at $190{ }^{\circ} \mathrm{C}$ and for $30 \mathrm{~min}$ followed by enzymatic hydrolysis is depicted in Fig. 4. As it was presented and discussed previously, the highest glucose yields were achieved after LFBD and hot water treatment at $190{ }^{\circ} \mathrm{C}$ for $60 \mathrm{~min}$ and after LFBD treatment at $190{ }^{\circ} \mathrm{C}$ for $30 \mathrm{~min}$ (Table 4). Since there was a higher solid recovery, i.e. $63.7 \%$ (Table 1) after treatment with LFBD for $30 \mathrm{~min}$, this treatment could be more promising for large scale processing due to the shorter duration time required. Therefore, the overall mass balance calculation was performed for this pretreatment condition. The glucan content of untreated straw was $30.38 \%$, which was increased to $40.73 \%$ after treatment at this condition (Table 2). After pretreatment, the straw was dried at room temperature and subjected to enzymatic hydrolysis using an initial substrate concentration of $25 \mathrm{~g} \mathrm{~L}^{-1}$. Finally, $6.6 \mathrm{~g} \mathrm{~L}^{-1}(17 \mathrm{~g})$ glucose and $2.6 \mathrm{~g} \mathrm{~L}^{-1}(6.6 \mathrm{~g})$ xylose was produced during enzymatic hydrolysis for $48 \mathrm{~h}$ (Fig. 3).

\section{Conclusions}

Wheat straw is one of the most abundant agricultural wastes all over the world. Hence, this lignocellulosic biomass is an attractive feedstock for biofuel production. The present study focused on investigating the effects of different pretreatment conditions using either hot water or the liquid fraction of biogas digestate. The results were evaluated both regarding changes in chemical composition and in the structure as well as in enzymatic digestibility. During this study it was proved that treatment using a waste liquid stream from biogas production, i.e. LFBD, can be applied as an economically feasible and environmentally friendly method with no need of addition of chemicals, aiming to increase the possibility for the utilization of released sugars. Both the compositional as well as the FTIR analysis showed solubilization of the hemicellulose, leading to enhanced yield of released sugars during the following enzymatic hydrolysis.

\section{Conflicts of interest}

There are no conflicts of interest to declare.

\section{Acknowledgements}

The authors gratefully acknowledge the financial support from the Swedish Centre for Resource Recovery at University of Boras,
Sweden as well as from the Research Institute of Biotechnology and Bioengineering, Isfahan University of Technology, Iran.

\section{References}

1 F. Talebnia, D. Karakashev and I. Angelidaki, Bioresour. Technol., 2010, 101, 4744-4753.

2 R. Ortiz, K. D. Sayre, B. Govaerts, R. Gupta, G. V. Subbarao, T. Ban, D. Hodson, J. M. Dixon, J. Iván Ortiz-Monasterio and M. Reynolds, Agric., Ecosyst. Environ., 2008, 126, 46-58.

3 D. Montane, X. Farriol, J. Salvadó, P. Jollez and E. Chornet, Biomass Bioenergy, 1998, 14, 261-276.

4 B. C. Saha, L. B. Iten, M. A. Cotta and Y. V. Wu, Process Biochem., 2005, 40, 3693-3700.

5 G. Mancini, S. Papirio, P. N. L. Lens and G. Esposito, Renewable Energy, 2018, 119, 608-614.

6 C. Chang, L. Deng and G. Xu, Ind. Crops Prod., 2018, 117, 197-204.

7 X. Yu, Y. Zheng, K. M. Dorgan and S. Chen, Bioresour. Technol., 2011, 102, 6134-6140.

8 X. Zhou, X. Zhou, X. Tang and Y. Xu, Bioresour. Technol., 2018, 261, 288-293.

9 S. Prasad, A. Singh and H. C. Joshi, Resour., Conserv. Recycl., 2007, 50, 1-39.

10 J. Xu, H. Chen, Z. Kádár, A. B. Thomsen, J. E. Schmidt and H. Peng, Biomass Bioenergy, 2011, 35, 3859-3864.

11 G. Gong, D. Liu and Y. Huang, Biosyst. Eng., 2010, 107, 67-73.

12 Q. Qing, Q. Guo, L. Zhou, X. Gao, X. Lu and Y. Zhang, Ind. Crops Prod., 2017, 109, 391-397.

13 F. Momayez, K. Karimi and M. J. Taherzadeh, Ind. Crops Prod., 2019, 129, 673-687.

14 S. Sajad Hashemi, K. Karimi and A. Majid Karimi, Fuel, 2019, 248, 196-204.

15 H. Chen, Y. Han and J. Xu, Process Biochem., 2008, 43, 14621466.

16 J. Xu, M. H. Thomsen and A. B. Thomsen, Biomass Bioenergy, 2010, 34, 334-339.

17 R. J. Patinvoh, E. Feuk-Lagerstedt, M. Lundin, I. Sárvári Horváth and M. J. Taherzadeh, Appl. Biochem. Biotechnol., 2016, 180, 1401-1415.

18 M. Taherzadeh and K. Karimi, Int. J. Mol. Sci., 2008, 9, 1621. 19 X. Zhuang, W. Wang, Q. Yu, W. Qi, Q. Wang, X. Tan, G. Zhou and Z. Yuan, Bioresour. Technol., 2016, 199, 68-75.

20 M. Laser, D. Schulman, S. G. Allen, J. Lichwa, M. J. Antal and L. R. Lynd, Bioresour. Technol., 2002, 81, 33-44.

21 S. G. Allen, L. C. Kam, A. J. Zemann and M. J. Antal, Ind. Eng. Chem. Res., 1996, 35, 2709-2715.

22 S. G. Allen, D. Schulman, J. Lichwa, M. J. Antal, M. Laser and L. R. Lynd, Ind. Eng. Chem. Res., 2001, 40, 2934-2941.

23 J. C. Solarte-Toro, J. M. Romero-García, J. C. Martínez-Patiño, E. Ruiz-Ramos, E. Castro-Galiano and C. A. Cardona-Alzate, Renewable Sustainable Energy Rev., 2019, 107, 587-601.

24 J. S. Kim, Y. Y. Lee and T. H. Kim, Bioresour. Technol., 2016, 199, 42-48.

25 R. Kumar, M. Tabatabaei, K. Karimi and I. Sárvári Horváth, Biofuel Res. J., 2016, 3, 347-356. 
26 K. Karimi and M. J. Taherzadeh, Bioresour. Technol., 2016, 200, 1008-1018.

27 P. Alvira, E. Tomás-Pejó, M. Ballesteros and M. J. Negro, Bioresour. Technol., 2010, 101, 4851-4861.

28 F. Momayez, K. Karimi, S. Karimi and I. Sárvári Horváth, RSC Adv., 2017, 7, 50537-50545.

29 F.-M. Pellera and E. Gidarakos, Waste Manag., 2018, 71, 689703.

30 A. Boonsombuti, O. Trisinsub and A. Luengnaruemitchai, Waste Biomass Valorization, 2019, DOI: 10.1007/s12649-01900622-z.

31 R. Nkoa, Agron. Sustainable Dev., 2014, 34, 473-492.

32 P. V. Plana and B. Noche, WIT Trans. Ecol. Environ., 2016, 202, 345-357.

33 K. Sasaki, T. Tanaka, Y. Nishizawa and M. Hayashi, Appl. Microbiol. Biotechnol., 1990, 32, 727-731.

34 K. P. Woli, T. Nagumo, K. Kuramochi and R. Hatano, Sci. Total Environ., 2004, 329, 61-74.

35 X. Lei, N. Sugiura, C. Feng and T. Maekawa, J. Hazard. Mater., 2007, 145, 391-397.

36 S. Astals, V. Nolla-Ardèvol and J. Mata-Alvarez, Bioresour. Technol., 2012, 110, 63-70.

37 K. Risberg, H. Cederlund, M. Pell, V. Arthurson and A. Schnürer, Waste Manag., 2017, 61, 529-538.

38 A. Sluiter, B. Hames, R. Ruiz, C. Scarlata, J. Sluiter D. Templeton, Standard Biomass Analytical Procedures, Determination of ash in biomass, National Renewable Energy Laboratory, 2008.

39 B. Adney and J. Baker, Laboratory analytical procedure, 1996, vol. 6, p. 1996.

40 A. Sluiter, B. Hames, R. Ruiz, C. Scarlata, J. Sluiter, D. Templeton and D. Crocker, Laboratory analytical procedure, 2008, vol. 1617, pp. 1-16.

41 M. Ø. Petersen, J. Larsen and M. H. Thomsen, Biomass Bioenergy, 2009, 33, 834-840.

42 J. A. Perez, A. Gonzáles, J. M. Olivia, I. Ballesteros and P. Manzanares, J. Chem. Technol. Biotechnol., 2007, 82, 929938.
43 T. Lloyd and C. E. Wyman, in Biotechnology for Fuels and Chemicals, Springer, 2003, pp. 53-67.

44 L. R. Lynd, Annu. Rev. Environ. Resour., 1996, 21, 403-465.

45 J. Bouchard, T. S. Nguyen, E. Chornet and R. P. Overend, Bioresour. Technol., 1991, 36, 121-131.

46 G. Garrote and J. Parajó, Wood Sci. Technol., 2002, 36, 111123.

47 S. P. Chundawat, B. Venkatesh and B. E. Dale, Biotechnol. Bioeng., 2007, 96, 219-231.

48 Y. He, Y. Pang, Y. Liu, X. Li and K. Wang, Energy Fuels, 2008, 22, 2775-2781.

49 R. Kumar, G. Mago, V. Balan and C. E. Wyman, Bioresour. Technol., 2009, 100, 3948-3962.

50 M. Poletto, H. L. Ornaghi and A. J. Zattera, Materials, 2014, 7, 6105-6119.

51 L. Dos Santos Silva, J. De Oliveira Carvalho, R. D. De Sousa Bezerra, M. S. Da Silva, F. J. L. Ferreira, J. A. Osajima and E. C. Da Silva Filho, Molecules, 2018, 23, 743.

52 X. F. Sun, F. Xu, R. C. Sun, P. Fowler and M. S. Baird, Carbohydr. Res., 2005, 340, 97-106.

53 M. Fan, D. Dai and B. Huang, in Fourier transform-materials analysis, InTech, 2012.

54 J. B. Kristensen, L. G. Thygesen, C. Felby, H. Jørgensen and T. Elder, Biotechnol. Biofuels, 2008, 1, 5.

55 M. S. Noori and K. Karimi, Biochem. Eng. J., 2016, 105, 197204.

56 A. Jeihanipour, K. Karimi and M. J. Taherzadeh, Biotechnol. Bioeng., 2010, 105, 469-476.

57 F. Momayez, K. Karimi and I. Sárvári Horváth, Energy Convers. Manage., 2018, 178, 290-298.

58 M. Shafiei, R. Kumar and K. Karimi, in Lignocellulose-Based Bioproducts, ed. K. Karimi, Springer International Publishing, Cham, 2015, pp. 85-154, DOI: 10.1007/978-3319-14033-9_3.

59 Q. Li, Y.-C. He, M. Xian, G. Jun, X. Xu, J.-M. Yang and L.-Z. Li, Bioresour. Technol., 2009, 100, 3570-3575.

60 A. B. Bjerre, A. B. Olesen, T. Fernqvist, A. Plöger and A. S. Schmidt, Biotechnol. Bioeng., 1996, 49, 568-577. 